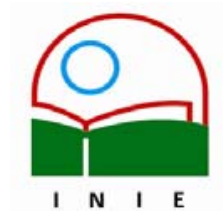

Actualidades Investigativas en Educación

Revista Electrónica publicada por el

Instituto de Investigación en Educación

Universidad de Costa Rica

ISSN 1409-4703

http://revista.inie.ucr.ac.cr

COSTA RICA

\title{
"RAPUNZEL" O LA NECESIDAD DE LIBERARSE: LECTURA CON ADOLESCENTES
}

\author{
"RAPUNZEL" OR THE NEED TO SET YOURSELF FREE: \\ READING WITH TEENAGERS \\ Volumen 7, Número 1 \\ Enero-Abril 2007 \\ pp. $1-24$
}

Este número se publicó el 30 de abril 2007

Silvia Méndez Anchía

La revista está indexada en los directorios:

LATINDEX, REDALYC, IRESIE, CLASE, DIALNET, DOAJ, E-REVIST@S,

La revista está incluida en los sitios:

REDIE, RINACE, OEI, MAESTROTECA, HUASCARAN

Los contenidos de este artículo están baj o una licencia Creative Commons 


\title{
"RAPUNZEL" O LA NECESIDAD DE LIBERARSE: LECTURA CON ADOLESCENTES \\ "RAPUNZEL" OR THE NEED TO SET YOURSELF FREE: READING WITH TEENAGERS
}

\begin{abstract}
Silvia Méndez Anchía ${ }^{1}$
Resumen: Con base en la premisa de que la lectura de textos literarios tiene una función formadora y que esta se acentúa en la adolescencia, me propongo demostrar que el cuento "Rapunzel" puede utilizarse como estrategia para explorar algunas situaciones que los sujetos adolescentes perciben como particulares en relación con su vida, pero que se inscriben dentro de grandes problemáticas estudiadas por varias disciplinas. Para ello, he identificado, desde dos marcos de referencia (sociológico y psicoanalítico), diversas problemáticas y discursos que se desprenden de la lectura del cuento realizada por dos mujeres adolescentes, quienes respondieron una guía de lectura y participaron en una entrevista a profundidad. Concluyo que la lectura y comentario del cuento hacen posible que una serie de experiencias que los sujetos adolescentes viven como únicas (como el embarazo de una amiga, las críticas de las personas adultas y las exigencias de padres y madres), ingresen en el circuito de los conocimientos generales al relacionarlas con los discursos y problemáticas en que se inscriben (por ejemplo, el discurso de la "crisis" de la adolescencia, el enfoque de derechos humanos, el mundo fantasmático materno). Por ello, recomiendo la lectura y comentario de textos literarios como estrategia didáctica para contribuir a la elaboración de la subjetividad de personas adolescentes.
\end{abstract}

Palabras clave: LITERATURA, LECTURA, ADOLESCENCIA, FORMACIÓN

Abstract: Based on the premise that reading literary works is a shaping exercise which becomes more intense during adolescence, I intend to show that the short story "Rapunzel" may be used as a strategy to explore certain situations that teenagers perceive as particular situations in relationship to their lives, but that are actually comprised within certain problem areas of greater magnitude that are studied under several disciplines. I have, to this effect, and within a sociological as well as a psychoanalytic framework, identified several problem areas and discourses derived from a reading of the short story by two teenage girls who provided answers in a reading guide and who participated in an in-depth interview. I arrive at the conclusion that reading and commenting on the short story make possible a number of experiences that teenage subjects experience and feel as unique occurrences (such as a friend's pregnancy, criticism from adults, and demands by parents) but that actually fall into the general knowledge circuit when they are associated with the discourses and problem areas within which they manifest themselves (for instance, the «crisis» of adolescence discourse, the human rights approach, the maternal phantasmal world). This is why I recommend reading and commenting literary texts as a didactical strategy to contribute to the development of teenage subjectivity.

Key words: LITERATURE, READING, ADOLESCENCE, SHAPING

\footnotetext{
${ }^{1}$ Máster en Psicopedagogía, de la Universidad de La Salle. Licenciada en Ciencias de la Educación con Énfasis en Docencia, de la Universidad Estatal a Distancia. Bachiller en Filología Española, de la Universidad de Costa Rica. Productora académica en la Universidad Estatal a Distancia y editora en la Universidad Nacional.
}

Correo electrónico: smendez@uned.ac.cr

Artículo recibido: 28 de febrero, 2007

Aprobado: 25 de abril, 2007 


\section{Introducción: La literatura y la formación de adolescentes}

Hace como dos meses yo me sentí como Rapunzel. Mi mamá me tenía encerrada, sólo con el estudio. En mi casa no hay mucho que hacer. Sólo estar encerrado en el cuarto. Yo le digo a mi mamá que ella debería ser más liberal, confiar más en uno.

(Inés, 16 años)

Un relato tradicional —aquí en su versión de los Hermanos Grimm (1995) — nos presenta a un hombre que, para satisfacer los antojos de su esposa, roba unos rapónchigos del huerto vecino, perteneciente a una bruja. Esta lo sorprende y le exige que, una vez nacida la criatura, se la entregue. Así ocurre, y cuando Rapunzel (también denominada en la tradición literaria como Rapónchigo o Nabiza) cumple 12 años, la bruja la encierra en una torre sin puerta ni escalera, a la que solo ella tiene acceso, pues trepa por la larga cabellera que la niña deja caer por la ventana. Luego de algunos años de encierro, el hijo del rey pasa por allí y queda impresionado con el canto de la joven. Usando la misma estrategia de la bruja, sube un día a la torre, pide a Rapunzel que sea su esposa y ella acepta pensando que él la querrá más que la señora. El príncipe la sigue visitando todas las noches hasta que ella pueda fabricar una escalera de seda por la cual abandonar su cárcel. Sin embargo, por una desafortunada expresión que se le escapa a Rapunzel, la bruja se entera de lo que sucede a sus espaldas y abandona a la joven en un desierto. Traspasado de dolor, el príncipe cae de la torre y pierde la vista. Vaga ciego desde entonces, hasta que un día llega al desierto y encuentra a su amada, con dos hijos mellizos. Se la lleva a su reino y viven felices muchos años.

Las funciones que puede cumplir un texto literario como este $-\mathrm{y}$ la literatura en general — se han planteado desde varias perspectivas. Una de ellas, quizás la más común, lo asocia con el "entretenimiento": se lee, así, para distraerse, por puro gusto. La práctica escolar, por su parte, busca la utilidad del texto, en cuyo caso lo presentaría, por ejemplo, como una manifestación del Romanticismo. El acercamiento que propongo aquí se relaciona con la capacidad formadora y transformadora de la lectura, como lo plantea Jorge Larrosa (1998). 
¿En qué consiste esta función de la lectura literaria? Michèle Petit $(1999,2001)$ se ha referido a este fenómeno que genera la actividad lectora en términos de "elaboración de la subjetividad": la lectura literaria contribuye a un proceso de simbolización que le permite al sujeto "iluminar" espacios de sí mismo que permanecían ocultos y pensar en otras posibilidades de inserción en la realidad. Este proceso se potencia en la etapa adolescente, dado que estas personas experimentan condiciones particulares: su percepción de ellas mismas se asocia con un mundo interior inquietante, a la vez que perciben hostilidad y exclusión en el mundo que las rodea.

Las premisas teóricas en que se sustenta esa visión de la capacidad de la literatura de "construir sujetos", tienen que ver con la concepción del lenguaje iniciada por los sofistas en la Antigüedad Clásica y que es retomada por la hermenéutica contemporánea y la teoría del lenguaje: la palabra no reproduce realidades, sino que las crea $\mathrm{y}$, dentro de esas posibilidades creadoras, se halla la configuración del ser humano como sujeto al orden de la cultura y al universo simbólico que la cultura representa. Al formar parte de ese orden simbólico, el sujeto se constituye mediante múltiples identificaciones con los otros, lo cual sucede con gran intensidad en la adolescencia, cuando identificaciones pasajeras ayudan a que el caótico mundo interno del sujeto se organice (Fernández Mouján, 2002). Como la literatura ofrece personajes o situaciones con las cuales se suelen identificar los sujetos, la lectura de tales textos adopta un carácter formativo, logrando incluso que lectores y lectoras sanen heridas emocionales y construyan formas de vida diferentes (Petit, 2001).

Mediante el contacto con textos literarios, las situaciones particulares por las que atraviesa el sujeto son delimitadas por el lenguaje, ingresando en el circuito de los conocimientos generales y perdiendo, con ello, su posible carácter estigmatizante:

Introducir los casos particulares en los casos generales [plantea Dolto, 1990, pp. 1156, refiriéndose a la vivencia del divorcio] permitiría desactivar en muchos niños la afrenta de no ser como precisamente les gusta ser a los niños: "todos iguales". Solo adoptando cierta distancia respecto a los sinsabores reales de la vida afectiva puede asumir un sujeto humano las características familiares que le pertenecen. Las repercusiones que ejercerán sobre su personalidad pueden ser inmediatamente transformadas, desde el momento en que el lenguaje delimita tanto las alegrías como las penas, y el niño hallará en la literatura diferentes apoyos a los fantasmas que su situación peculiar le suscita. 
En concordancia con lo planteado por Dolto, Michèle Petit sostiene que la lectura puede presentar, a las personas jóvenes, que las situaciones que viven como únicas, en realidad forman parte de la vida de muchas otras personas, es decir, que mediante los textos literarios se puede reconocer uno como parte de la humanidad. Así lo plantea esta autora cuando se refiere a la lectura en la adolescencia:

Edad en la que no se sabe cómo definirse. Y en la que se tiene miedo también de las definiciones. Un momento en que habría que estar, más que en otros, informado sobre lo que le está pasando a uno. Encontrar palabras que le muestran a uno que en el fondo no hace más que compartir afectos, tensiones y angustias universales, aun cuando se declinen de forma muy diferente según hayamos nacido niña o niño, rico o pobre, en tal o cual rincón del mundo. (1999, p. 50)

Estas propuestas acerca de las posibles funciones de la literatura en la formación de niños, niñas y adolescentes, se basan en una perspectiva según la cual el sujeto es un ser secundario en relación con el lenguaje. La verdad del sujeto está en su palabra, pero ese discurso que le define un lugar en el mundo proviene, en buena parte, de otros sujetos. Por lo tanto, trabajar con el discurso de adolescentes implica trabajar con el de los otros que atraviesan sus palabras: el mundo fantasmático de padres y madres; las demandas docentes, de sus familiares y amistades; el mensaje de los medios de comunicación colectiva, para citar unos cuantos ejemplos. Por ello se impone una lectura de ese discurso como una "polifonía textual" (para utilizar una expresión de Bajtín, 1986).

\section{Propósito y metodología}

Con base en las premisas anteriores, me propongo demostrar que el cuento "Rapunzel" puede utilizarse como estrategia para explorar algunas situaciones que los sujetos adolescentes perciben como particulares en relación con su vida, pero que se inscriben dentro de grandes problemáticas estudiadas por varias disciplinas. Por situaciones particulares entiendo no necesariamente las alusiones a su vida personal, sino la visión y opinión que tales sujetos tienen de las situaciones que se les presentan en el relato, es decir, su forma particular de leer esos grandes asuntos que el texto sugiere o provoca. 
Para ello, he identificado diversas problemáticas y discursos que se desprenden de la lectura del cuento realizada por dos mujeres adolescentes: Inés, de 16 años, estudiante de noveno grado; y Diana, de 17 años, quien cursa el undécimo grado. Ellas contestaron por escrito una guía de lectura que constaba de los siguientes puntos:

1) ¿Por qué la bruja encerró a Rapunzel a los 12 años?

2) Rapunzel engañaba a la señora Gothel. ¿Qué opina usted de eso?

3) ¿Qué le parece el castigo que la señora Gothel le impuso a Rapunzel?

4) ¿Y lo que le pasó al príncipe (ceguera)?

5) Rapunzel está siendo sometida a un juicio por desobedecer a la bruja, y le ha pedido a usted que se encargue de su defensa. Escriba los principales argumentos que usted utilizaría para defenderla. (Con base en "Yo le defiendo", estrategia de animación a la lectura planteada por Sarto, 1998.)

Luego, las adolescentes participaron en una entrevista individual para profundizar en algunos puntos relacionados con sus respuestas a la guía.

Finalmente he interpretado, a la luz de diversos marcos de referencia, la relación que se establece entre esas problemáticas generales, las situaciones particulares de las dos lectoras y el relato literario. En cuanto a los marcos de referencia empleados para la interpretación, estos varían dependiendo de la problemática tratada; así en algunos casos recurro a explicaciones de índole sociológica, mientras que en otros el psicoanálisis provee un sustento teórico pertinente. Al respecto, coincido con lo que plantea Charles Sarland (2003, p. 13) sobre la necesidad de considerar diversos marcos explicativos al estudiar la recepción de la literatura por parte de niños y niñas (y adolescentes en nuestro caso): “...si queremos entender lo que sucede cuando leen los niños, tenemos que valernos de todas las teorías que sean pertinentes para explicar cómo funcionan las obras de ficción, y de todas las investigaciones pertinentes acerca de cómo funcionan los niños".

\section{Interpretación: Inés, Diana y Rapunzel}

En los apartados siguientes, presento los resultados de este estudio. Para su exposición, me centro no tanto en la respuesta de cada joven al texto literario, sino más bien en el relato mismo para, a partir de él, identificar diversos tópicos que se desprenden de la puesta en 
contacto de las lectoras con el cuento. De manera transversal establezco también, en aquellos casos en que me es posible, una relación entre la historia de las personas adolescentes y las historias literarias, con el fin de demostrar el continuum entre la narración leída por cada persona y el conjunto de historias de que se compone cada sujeto que, al entrar en contacto con el texto, se activan como criterios de comprensión de cada relato.

\section{1 "Una edad de errores y tonteras"}

Rapónchigo era la niña más hermosa del mundo. Cuando cumplió doce años, la bruja la encerró en una torre que se encontraba en un bosque y que no tenía puerta ni escalera, tan sólo una ventanita en lo alto.

(“Rapónchigo")

El discurso adulto estigmatiza la adolescencia como una etapa problema: el embarazo, la delincuencia, las drogas, el fracaso escolar y las pandillas son denominadores comunes que la definen como una edad riesgosa.

Sin embargo, esa imagen de una crisis ineludible que se debe superar, es una construcción de la clase adulta. Fize (2001) lo plantea tajantemente: la crisis de la adolescencia no existe. No es otra cosa que el resultado de la dominación de la clase adulta sobre la joven generación, que esta última acaba interiorizando, como podemos ver en la respuesta de Inés a la siguiente pregunta: ¿Por qué cree usted que la bruja encerró a Rapunzel a los 12 años? Como ya es adolescente y todo. Está en la edad en que se cometen más errores y se hacen más tonteras. Por ejemplo, yo tengo una amiga que está embarazada. Otros errores y tonteras que comete la gente son las drogas y el licor; como la gente no piensa, caen más rápido, son más fáciles de manejar, porque son influenciados por los amigos. (El resaltado es de la autora.)

Dos elementos relacionados con la definición de la adolescencia, como etapa problema, aparecen en el discurso de esta joven: el embarazo y las drogas.

¿Por qué el embarazo se presenta como una característica de la problemática que puede afectar a la población adolescente? Según Fize (2001), durante el siglo XIX la "adolescencia" 
se confunde con la "pubertad" y el peligro se centra en el sexo, razonamiento que permite imponer control a este grupo etario. Al confundir "adolescencia" y "pubertad", se ocultan todos los demás ámbitos de transformaciones que suceden a la persona adolescente (el desarrollo intelectual, el proyecto de vida...), para centrarse en la protección ante el peligro que representan las demandas hormonales.

En este cuento, el embarazo es fuente de males (los antojos de la mujer preñada desencadenan los problemas), pero también forma parte del final feliz: Rapunzel procrea unos gemelos y encuentra de nuevo a su príncipe, con quien disfruta muchos años. Justamente, en esa doble dimensión se presenta el embarazo a las jóvenes de hoy. Rojas (2002, p. 57) señala, al respecto, que ellas abordan este tema "de manera ambivalente, sobre todo del riesgo de quedar embarazadas [...], pero que a la vez 'es una meta, una ilusión a futuro"'.

Otro tema que se hace presente en el discurso de esta lectora es el de las drogas. Si bien es cierto la problemática asociada con el consumo de tales sustancias encuentra motivaciones profundas en la historia de cada sujeto, diversas situaciones propias de la adolescencia hacen que se tenga propensión a probarlas. Por ejemplo, muchos experimentan una sensación de vacío interior, así como falta de interés o aburrimiento y la sensación de no ser amados (Dolto, 1993); también existe una curiosidad propia de esta edad que, junto con la necesidad de identificarse con el grupo de semejantes y el atractivo de lo prohibido, crean situaciones en que las personas son más vulnerables al consumo de drogas (Baldiz y Rosales, 2005).

Sin embargo, no se puede descontextualizar estas situaciones y atribuirlas únicamente a la etapa de la adolescencia. Es necesario apreciarlas en el marco de lo que Fize (2001, p. 66) ha definido como "un estado social degradado y una situación económica saturada de inactividad y de precariedad". Como veremos más adelante, a la población adolescente se le niegan posibilidades de ejercer sus derechos ciudadanos, con lo que se la inhibe de realizarse plenamente.

\section{2 "La mayoría de la gente es concha con los adolescentes"}


El príncipe trepó, pero arriba no encontró a su querida Rapónchigo, sino a una bruja que le miraba con malos y pérfidos ojos.

— ¡Hola! —exclamó la bruja irónicamente-. Vienes a ver a tu queridita, pero el lindo pajarillo ya no está en la jaula y no cantará más; el gato se lo llevó y ahora te sacará a ti los ojos. Perdiste a Rapónchigo para siempre; nunca volverás a verla.

(“Rapónchigo")

Desde el momento en que se confunde "adolescencia" con "pubertad", la persona es estigmatizada y se la asocia con situaciones de peligro. En Carrie, la conocida obra de Stephen King, se relaciona la primera menstruación de una muchacha con el despertar de un poder extraordinariamente destructivo (Sarland, 2003).

Esa caracterización de la juventud como un sector peligroso, problemático, vulnerable, transgresor del orden social, se relaciona con una respuesta de la clase adulta que consiste en visibilizarla de manera descalificante; al asociar a la juventud con la generación de problemas, las personas adultas suelen reaccionar con temor y rechazo (Krauskopf, 2000).

Profundizando en su respuesta a la pregunta sobre la razón del encierro de Rapunzel a los 12 años, Inés se refiere a las palabras que la bruja dirige al príncipe luego de que destierra a la joven:

¡Qué concha ella! Decirle eso tan feo de primera impresión. La mayoría de la gente es concha con los adolescentes: [dicen que] los de mi grupo juvenil son unos desordenados, un despelote, una pura fiesta. ¿Por qué razón? Porque la sociedad ha estado marcado que los adolescentes son lo peor, no sirven para nada, no tienen responsabilidades. Uno, igual que un chiquito o un señor, tiene algún objetivo en la vida. Por algunos que son malos, los generalizan a todos.

Como lo expresa esta lectora, en el discurso adulto la adolescencia se reviste de connotaciones negativas. Es como si existiera un rechazo común hacia unas personas que, aunque son menores de edad, no poseen los rasgos "graciosos" de los niños y las niñas aunque hago la salvedad de que también estos últimos son objeto de rechazo y maltrato, de 
manera quizá menos evidente-, pero tampoco resultan "productivas" como las personas adultas y que, peor aún, suelen poner en entredicho la autoridad de estas.

Frente a tales estereotipos, las personas adolescentes reaccionan reclamando que las situaciones que viven no son exclusivas de su edad. "Uno, igual que un chiquito o un señor, tiene algún objetivo en la vida", dice esta joven, y concuerda con lo que apuntan los estudiantes y las estudiantes del Colegio Marista de Alajuela cuando advierten que las situaciones por las que atraviesan -y por las cuales son objeto de crítica- no difieren grandemente de las que suceden a las personas adultas: "Las edades no definen a las personas', 'somos indecisos pero ¿cómo no?, si tenemos que escoger una carrera, el trabajo, casarse o no, además, los adultos están también en si este trabajo o no, casarse o no, divorciarse o no"' (Rojas, 2002, p. 46).

Efectivamente, si fuera necesario hablar de crisis, esta palabra debería aplicarse por igual a todos los componentes de la sociedad. Y así un alto grado de responsabilidad vendría a recaer sobre las instituciones y estructuras sociales, en las cuales la mayor participación la tienen las personas adultas. Para Fize (2001), la supuesta crisis de la población adolescente es el resultado de una sociedad que le niega un estatus y que no le ofrece muchas esperanzas: una sociedad sometida a las leyes del mercado, sin moral colectiva ni razón individual, con un debilitamiento de los grupos primarios e intermedios de socialización (la familia, la escuela, los partidos políticos, los sindicatos...) y en la cual la burocracia, el tecnocratismo y el individualismo lo dominan todo.

\section{3 "Y yo la cuidaré como una madre"}

Entonces la bruja se apaciguó y le dijo:

- Si es como dices te permitiré que cojas todos los rapónchigos que quieras; sólo te pongo una condición: tendrás que darme a la criatura que tu mujer traiga al mundo. No le pasará nada, y yo la cuidaré como una madre.

(“Rapónchigo") 
En una lectura superficial del cuento, madre y bruja aparecen como personajes opuestos, colocados a cada lado de la dicotomía bondad/maldad; sin embargo, en lo profundo, donde ocurren procesos de desplazamiento y condensación, son uno solo: la mujer deseosa de descendencia y la bruja ingrata que encierra a la hija en una torre constituyen, en lo profundo, manifestaciones de una misma función, la materna.

No obstante, en el cuento de hadas esas dos caras de la moneda aparecen separadas en el plano superficial, como expresión de un mecanismo disociador que permite que niños y niñas conserven una imagen positiva de la madre, cuando esta se ve amenazada por una relación difícil de manejar o de comprender (Bettelheim, 1988). Así, los rasgos de bondad y maldad se encarnan en distintos tipos de personajes femeninos asociados con la función materna: madre, madrastra y bruja son los más comunes, pero también encontramos otros como el hada madrina y la mujer del ogro.

Como ya he señalado, en este cuento la madre hambrienta, vacía, con un deseo devorador insaciable, no es otra que la bruja a quien ofrenda a su hija para pagar los rapónchigos ingeridos. Y la niña —nombrada igual que la planta que sirvió de sustento a su progenitora - es el objeto que vendrá a saciar el hambre de la madre-bruja, quien la encierra en una torre para separarla del mundo.

La posibilidad de constituir el alimento de una bruja (como sucede en el cuento de "Hansel y Grethel") o de un temible ogro (como en "Pulgarcito" o en "Juan y las habichuelas mágicas"), se asocia con fantasías que tienen un profundo asidero en la vida anímica infantil. Dorothy Bloch (2000) plantea que, dada la vulnerabilidad del niño y la niña y el poder de su pensamiento mágico, el miedo a perder su propia vida a manos de sus padres es su principal preocupación. En el caso de las adolescentes, una relación con una madre asfixiante, controladora, que inhibe la separación de su hija como sujeto, puede ser motivo de un cuadro anoréxico; para Baldiz y Rosales (2005), renunciar al alimento expresa un rechazo de los caracteres sexuales secundarios, que confrontan a la adolescente con la prueba real de su identidad sexual y, en consecuencia, con la figura de su propia madre; "la anorexia es crear un hueco donde la madre no se meta", afirma la psicoanalista Sonia Cruz (2004).

Profundizando en la respuesta a la pregunta sobre el motivo por el cual la bruja encerró a Rapunzel, Diana argumenta lo siguiente: "La bruja tiene encerrada a Rapunzel, porque 
nunca logró ser feliz y trajo como respuesta la soledad y cuando una persona no acepta su condición de vida busca que otros alivianen su pesar". Por su parte, Inés señala que "Rapunzel era como un tesoro para la bruja, porque nunca había tenido hijos. Por eso la tiene encerrada".

Rapunzel forma parte de su madre. Satisface el hambre de esta. Llena sus vacíos, compensa su soledad. Por eso la madre no la quiere compartir: buscando que la joven "aliviane su pesar" no aceptado, la encierra en una torre a la cual solamente ella tendrá acceso. La forma como las adolescentes leen este cuento, pone en primer plano lo que el psicoanálisis denomina "mundo fantasmático", donde "lo fantasmático" tiene que ver con una representación inconsciente relacionada con la satisfacción imaginaria de un deseo (Fedida, 1979); los sueños, fantasías, anhelos y carencias experimentados por el sujeto se extienden a la realidad y determinan, en el caso que nos ocupa, la generación de expectativas y demandas de la madre en relación con su hija. Rapunzel es producto —ese "tesoro"— de la historia de una madre marcada por la infelicidad y la soledad. Una cita de Mannoni (1984, p. 22) ilustra esa demanda inconsciente que plantea la madre desde mucho antes del nacimiento del hijo:

¿Qué es, para la madre, el nacimiento de un niño? En la medida en que lo que desea durante el curso de su embarazo es, ante todo, la revancha o el repaso de su propia infancia; la llegada de un niño va a ocupar un lugar entre sus sueños perdidos: un sueño encargado de llenar lo que quedó vacío en su propio pasado, una imagen fantasmática que se superpone a la persona 'real' del niño. Este niño soñado tiene por misión restablecer, reparar aquello que en la historia de la madre fue juzgado deficiente, sufrido como una carencia, o prolongar aquello a lo que ella debió renunciar.

Desde las demandas inconscientes de ese mundo fantasmático, la señora Gothel impide que Rapunzel se construya como un sujeto diferente de ella. Por eso mismo, no puede permitirle que conozca a un hombre, ya que la joven le pertenece. Justamente Bettelheim (1988) ve, en este cuento, la historia de una niña que inicia su adolescencia y una madre celosa que le impide que alcance su independencia. Y así lo vive Inés, quien comenta lo siguiente: "Mi mamá es muy celosa. Yo le digo: Usted desearía que yo fuera sólo para usted".

El sano desarrollo de una adolescente puede verse comprometido por una madre posesiva, que impide que la hija salga del ámbito familiar en busca de otros horizontes, representados 
en este cuento por la relación amorosa con algún joven. Para que el sujeto adolescente entre en contacto con otros objetos de amor distintos de los padres y se cumpla con la prohibición del incesto, es necesario que el grupo familiar abra puertas y ventanas, de modo que aquel pueda salir y cumplir así con una de las tareas más importantes de la adolescencia: elaborar su propio proyecto de vida.

En la lectura que Diana e Inés hacen del personaje de la bruja, es clara su asociación con los progenitores, en especial con la madre. Por la plurisignificación del texto literario y por la variedad de experiencias de las jóvenes con sus respectivas figuras maternas, la comprensión del texto adquiere aquí algunos matices, a los que me refiero a continuación.

Para interpretar al personaje de la señora Gothel, es necesario tomar en cuenta que el texto literalmente la llama bruja y que ella encierra a Rapunzel en una torre, negándole toda posibilidad de salir. Esto la hace objeto de censura. Así lo plantea Diana cuando opina sobre el engaño de la muchacha a la señora Gothel:

Cualquier ser humano que experimente opresión reaccionaría defendiendo sus intereses; porque cada persona va tras una meta, propósito, etc. Y si mentir era la única forma de proteger su amor lo haría. [...] No hubiese importado si hubiera sido un príncipe o no, porque las circunstancias en que ella vivía su entorno era la única posibilidad que tenía su corazón: amar libremente, ya que su vida era totalmente manejada.

Esta joven toma partido por Rapunzel, el personaje que es objeto del encierro, y la defiende razonando que el fin justifica los medios.

En oposición a este punto de vista, Inés identifica bruja y progenitores, y le atribuye un carácter benéfico a su actitud represiva en contra de Rapunzel. Veamos lo que plantea:

La bruja es como esos tipos de papás muy protectores: quiere solo el bien para ella. Casi siempre los hijos quieren salir, pero los papás son el límite. Los cuidan mucho [...] Que Rapunzel engañara a la señora Gothel no está bueno, porque al final era la que la había cuidado y es bueno ser sincero siempre. Uno tiene que ver cómo puede arreglar la situación. (El resaltado es de la autora.)

Este comentario de Inés alude a diversas situaciones relacionadas con la adolescencia. A continuación, lo analizaré presentando primero la interpretación de Bettelheim; luego, de 
acuerdo con el concepto de la "resistencia al cambio"; más adelante, según el tema de la culpabilidad adolescente, para finalizar con el planteamiento —el más radical de estos— de Alice Miller sobre la agresión por el mundo adulto.

Inés censura a Rapónchigo por su desobediencia y por no considerar la manera de arreglar la situación y reconocerle a la señora Gothel el "cuidado" que le había proporcionado. Bettelheim (1988) plantea que, efectivamente, la bruja de este cuento no es un personaje del todo negativo, pues su conducta egoísta obedece a su amor por la niña, a su deseo de retenerla a su lado el mayor tiempo posible; "amar tan egoísta y absurdamente es algo erróneo pero no malvado", dice este autor (p. 211).

Ese deseo egoísta de los padres tiene su correlato en el deseo del niño o la niña de que se le retenga, lo cual explica el "lapsus" que comete Rapunzel cuando le dice a la señora que ella pesa más que el joven que trepa por sus trenzas todas las noches. Otro comentario de Inés dice lo siguiente:

Eso [de haber aceptado ser la esposa del príncipe] es muy arriesgado, porque después el muchacho puede ser un mal hombre y después se puede arrepentir de haber dejado a la señora. Debió haberle dado más tiempo, conocerlo más y hablarlo con la señora, para que después ella no se enojara tanto. Si le hubiera dicho, hubiera reaccionado mal, pero con el tiempo hubiera tenido apoyo de la bruja.

Vemos aquí, la "resistencia al cambio" de que hablan Etcheberry y otros (2006), para referirse a la ambigüedad que caracteriza las relaciones y sentimientos de las personas adolescentes, y cuya toma de decisiones se halla marcada por un anhelo y a la vez un temor a la libertad, razón por la cual buscan la manera de que otros sigan decidiendo por ellas. Rapunzel posterga el abandono de la torre, que depende del tiempo que dure tejiendo una escalera de seda $y$, finalmente, se delata ante la bruja manifestándole, "sin querer queriendo", que el príncipe la visita todas las noches.

Otra forma de interpretar este apoyo a la actitud de la madre-bruja tiene que ver con el tema de la culpabilidad adolescente. Según Dolto, esta se origina en la incapacidad de algunos padres y algunas madres de enseñar que las prohibiciones son relativas (con excepción de la del incesto), y que estas funcionan como protección ante el peligro. Esta ausencia de relativización de las prohibiciones produce que las figuras paterna y materna aparezcan 
como todopoderosas para sus hijos e hijas adolescentes. Ello les impide, a los hijos, ejercer un espíritu crítico que los impulse a desobedecer de manera reflexiva y voluntaria (Liaudet, 2002).

"Si yo fuera madre y tuviera una hija adolescente que me cuestiona, sentiría que no he hecho mi labor." Inés ha incorporado una visión incuestionable de la autoridad de los padres, contraria a la esencia misma del ser adolescente. Explicando una frase de Freud, Dolto (1999) señala la crítica de la educación familiar como un requisito para que la persona joven gane autonomía.

Muchas veces las figuras de autoridad interpretan como una sublevación el que se las critique, con lo cual se inhibe el desarrollo de las ideas de las personas adolescentes. Para sostener su posición de autoridad, es común que las personas adultas recurran a mecanismos que las hagan ver como poseedoras de la verdad absoluta. Al respecto, es necesario indicar que no sólo el sujeto adolescente sufre cambios, sino también su familia, especialmente su padre y su madre, quienes deben elaborar varios duelos asociados con sus hijos e hijas y con ellos mismos, uno de los cuales incluye la pérdida de una imagen omnipotente y omnisapiente para quienes hasta hace poco eran sus hijos pequeños; asimismo, existe un fenómeno denominado la "pubertad de los padres", que se caracteriza por fijar demasiado a los hijos e hijas en la dependencia familiar, "impidiendo o limitando en exceso sus relaciones con el exterior, es decir, obstaculizando su deseo natural de ser autónomo y de abrirse al mundo" (Fize, 2001, pp. 52-53).

Finalmente, Inés introduce el tópico de "por tu propio bien", con que el discurso adulto justifica el infligir malos tratos a las personas menores de edad. Alice Miller (1998) explica la situación por la que atraviesan los niños pequeños víctimas de malos tratos $-y$ aquí interpreto el encierro de Rapunzel como una manifestación de estas actitudes de violencia que pretenden tener una justificación "pedagógica" - señalando que estos ponen en duda el carácter trágico de sus experiencias, a la vez que intentan convencerse de que la crueldad que se les inflige tiene como objetivo su propio bienestar, pues responde a una medida pedagógica necesaria; en la mayoría de los casos, intentan comprender las motivaciones de sus agresores y simpatizar con estos.

La reacción normal a una agresión debería ser de enfado y dolor. Sin embargo, en un entorno perjudicial, al niño se le prohíbe enojarse y, en su soledad, el dolor le resultará 
insoportable. El niño debe entonces ocultar sus sentimientos, reprimir el recuerdo del trauma e idealizar a su agresor. Más adelante, no sabe lo que le ha pasado. (Miller, 1998, p. 272)

He pasado revista a diferentes interpretaciones que, con base en la lectura de Inés y Diana, pueden plantearse acerca del personaje y las acciones de la bruja. Como continuación de esta temática, analizaré seguidamente qué opinan las lectoras sobre el castigo que la bruja le impuso a Rapunzel.

\subsection{La soledad del desierto}

Y fue tan despiadada que se llevó a la pobre Rapónchigo a un desierto, donde vivía con gran penuria en la desolación.

(“Rapónchigo")

La adolescencia es una edad de búsqueda de otros a partir de los cuales definirse. Por eso mismo, es la época de las amigas, los amigos, las "barras", la vida social (fiestas, grupos, actividades comunales)... Hay una necesidad de estar con otras personas más allá del grupo familiar, que vive también en crisis por los cambios que conlleva tener a un sujeto adolescente en casa.

En tales circunstancias, ¿qué significado adquiere el castigo del desierto, que la bruja le impone a Rapunzel? La palabra "desierto" alude a algo despoblado, solo, deshabitado, es decir, a la ausencia de socialidad. También se refiere a un "terreno arenoso o pedregoso, que por la falta casi total de lluvias carece de vegetación o la tiene muy escasa" (RAE, 2001), asociándose con improductividad, con ausencia de vida. Un desierto es, para Tolstoi (1991), un camino que se torna cada vez más penoso y fatigoso, justamente como, según el escritor ruso, fue su propia adolescencia.

Siendo tan importante en esta etapa de la vida el contacto con otras personas y estando presente una sensación de muerte producto de las transformaciones sufridas, enviar a esta joven a un lugar deshabitado y carente de vida puede interpretarse como una sanción extrema. Así lo lee Inés: 
El castigo que la señora Gothel le impuso a Rapunzel fue muy extremo, porque al final la hubiera castigado con otras cosas (por ejemplo, encerrándola en otra torre). A mí el castigo más extremo ya me los han hecho: quitar la música, quitar el tele, me han tenido sin salir, me han quitado el celular (eso fue lo que más me dolió). Tal vez meterme en un convento, sin salir sólo un par de días al año. Se pierde estar en el mundo, viviendo como es todo; cuando uno sale, uno se siente como extraño, no se relaciona con otras personas, no puede tener oportunidades (estudiar, trabajar...). La casa es a veces un convento, si lo castigan a uno, cuando le quitan el teléfono.

Privar de la música, la televisión, el teléfono celular y las salidas se asemeja al encierro en una torre, pues implica un extrañamiento del mundo, es decir, el no poder estar en contacto con otras personas y con las oportunidades que tales relaciones suelen conllevar.

Así como el castigo impuesto a Rapunzel es considerado muy severo, también el que sufre el príncipe. "Lo que le pasó al príncipe también fue muy extremo. Porque a él le gustara Rapunzel no era necesario lastimarlo así, con algo tan fundamental. ¿Qué puede significar? Un significado muy cruel; uno no tiene potestad para quitarle la vista a alguien", dice Inés.

Ante esta visión del príncipe y Rapunzel como seres pasivos, que reciben una sanción, Diana incorpora un aspecto fundamental que tiene que ver con las adquisiciones intelectuales y de autonomía relativa que va teniendo la persona adolescente: las decisiones y la responsabilidad sobre sus propios actos. En relación con el castigo que sufre el príncipe, ella dice lo siguiente: "Toda decisión trae una consecuencia. Alcanzar los sueños y persistir pese a los peligros no en todos los casos es positivo, diferentes recursos o caminos pueden traer menos consecuencias negativas".

Esta interpretación del castigo se centra en las personas castigadas: Rapunzel ( $\mathrm{y}$, en su respuesta, la lectora también se centra en ella misma cuando es objeto de castigo) y el príncipe. Diana, en cambio, lo analiza a la luz de quien impone la sanción; en este caso no se refiere específicamente a la bruja, sino que su respuesta generaliza la situación; dice así: "Que para muchas personas tener dominio y poder sobre otras es el único recurso ante la propia flaqueza y debilidad que posee".

Alice Miller (1998) explica esa necesidad de poder que lleva a las personas a dominar y castigar a los más débiles (en este caso, los niños, niñas y adolescentes) como una forma 
de identificarse con el agresor de que fueron objeto en su infancia. Muchas personas que han sufrido los efectos de la violencia física y moral en sus primeros años de vida, repiten, en su vida adulta, esa violencia con las personas que están a su cargo.

Ahora bien, lo cierto es que en estas dos visiones subyace siempre la idea del castigo que impone una persona adulta, el cual puede ser la consecuencia de un acto del sujeto adolescente. Desde el adultocentrismo, se controlan las conductas de las personas jóvenes a partir de castigos, cuando lo que estas demandan, por el contrario, son posibilidades de comunicación para exponer sus necesidades y que se valoren sus aportes; "sienten que en múltiples ocasiones se les castiga sin justificación, sin tener la convicción de que es por tal o cual razón", como han señalado las participantes en el estudio hecho por Rojas (2002, p. 70). Esas relaciones unilaterales de autoridad desconocen —como veremos en el próximo apartado- el carácter de sujeto de niños, niñas y adolescentes.

Me da cólera, porque me castigan por algo sin sentido; me dicen que usted es una irresponsable, cuando uno hace tareas, lava la ropa, llega 15 minutos después de la hora. Yo le digo a mi mamá que castigándome o pegándome... es mejor que lleguen a uno, que lo sienten o le hablen o le expliquen. A veces me dice "A usted sí le faltó que le pegaran", o "Usted es una malcriada", y yo le respondo "Sí, una mal-criada, no es mi culpa". (Inés)

Mi mamá dice que hablar conmigo es como hablar con la pared, que si algo no le gusta no me lo va a decir, porque no le hago caso. (Diana)

En los comentarios anteriores, se nota la decisión de castigar, en vez de establecer canales comunicativos. Ello puede explicarse también a la luz de los cambios que sufren los progenitores y otras personas adultas cuando conviven con adolescentes. La inseguridad que genera el recuerdo de sus propias experiencias cuando fueron adolescentes, hace que muchas personas adultas reaccionen de maneras distintas, como con expresiones de duelo, competencia, hostilidad, celos y ansiedad. Analizando esta situación desde la perspectiva de Alice Miller (1998), es posible asociar la rigurosidad, que inhibe las posibilidades de comunicación entre las diferentes generaciones, con una identificación con el agresor; por el contrario, una identificación con la vulnerabilidad propia de los sujetos adolescentes debería llevar a una reacción empática. 


\subsection{Rapunzel, una chica con derechos}

Empecé esta interpretación refiriéndome al discurso adulto que plantea la adolescencia como una crisis y define este momento de la vida en términos de problemas tales como las drogas, el embarazo y la delincuencia. Justamente, el discurso de Inés dejaba ver la influencia de esa forma de pensar y de valorar la etapa adolescente, al explicar que el encierro que la bruja impuso a Rapunzel se debió a que se hallaba en esa etapa de la vida "cuando se cometen muchos errores".

Ahora bien, esta misma estudiante incorpora otro discurso: el del enfoque de los derechos humanos, para basar su defensa de Rapónchigo. Este enfoque deja de lado el énfasis estigmatizante y reduccionista de la adolescencia como problema, para adoptar un paradigma de la juventud ciudadana, que le reconoce a este grupo etario un lugar en la sociedad, con posibilidades de acción y de hacer aportes al bienestar colectivo.

Así plantea Inés su defensa de Rapunzel:

Si yo tuviera que defender a Rapunzel en un juicio por desobedecer a la bruja, los principales argumentos serían basados sobre los derechos humanos tales como: 1. Respeto a la vida. 2. Educación. 3. Familia. 4. Trabajo. 5. Por último el derecho a la libertad, porque nadie se merece estar encerrado, sin haber cometido algún delito, ya que se le aísla del mundo exterior, y le impiden tomar sus propias decisiones, no se puede relacionar con las demás personas, entre muchos aspectos más. (El resaltado es de la autora.)

Coincide en ello con Diana, quien argumenta lo siguiente:

a) Ningún ser humano puede someter $u$ obligar a otro ser humano a perder su libertad.

b) Se desconoce si ella poseía todas sus necesidades básicas (vida social, amor, alimentación, abrigo, educación, familia, etc.).

c) Le fue negado el derecho de convivir con sus padres. Esto podría verse como un secuestro o rapto. (El resaltado es de la autora.)

Contrariamente al discurso que presenta la adolescencia como crisis, el enfoque de los derechos humanos de la niñez y la adolescencia reconoce que este grupo está formado por personas con necesidades singulares (no necesariamente con conductas anómalas), las Volumen 7, Número 1, Año 2007, ISSN 1409-4703 18 
cuales pueden explicarse por la etapa de formación en que se hallan, y que pueden establecer relaciones reflexivas con las personas adultas.

Dentro de este enfoque, que introducen en su discurso estas jóvenes al defender a Rapónchigo, se identifica claramente el derecho a la libertad. También en el estudio realizado por González Vargas (2004, p. 200), las participantes (alumnas de sexto grado de una escuela alajuelense) hablaron del tema de la libertad como lo contrario de la esclavitud, y señalaron que "la esclavitud se presenta cuando no se pueden tomar decisiones propias y por lo tanto la persona se ve sometida a situaciones, o está bajo el mando de otro, el cual no considera para nada sus decisiones, deseos ni necesidades".

Según Güendel (2000), el valor de la libertad adquiere un significado diferente en el enfoque de derechos humanos, alejándose del sentido que se le atribuía en los paradigmas socialista y liberal. Estos plantearon la institucionalidad de tales derechos con base en ciertos atributos como la raza, lo masculino y la adultez, invisibilizando diferencias y especificidades (por ejemplo, las relacionadas con condiciones de género y edad), cuya consecuencia para estos sectores fue un disfrute limitado de la igualdad y la libertad.

El valor de la libertad desde el enfoque de los derechos humanos es renovador, pues toca ciertas fibras sociales, en particular espacios antes considerados de la intimidad, como la familia y, hasta cierto punto, la escuela. Tratándose de sujetos adolescentes, ello reviste una importancia particular, por dos razones fundamentales: por un lado, los visibiliza como sujetos de derecho y, por otro lado, destaca que la relación que establecen con las personas adultas está mediada por el poder.

De ello se desprende también una visión diferente de la ciudadanía. Siguiendo a Güendel (2000), esta ya no es sólo un concepto general, sino que se reconocen ciudadanías específicas, dentro de las cuales el caso de la niñez y la adolescencia es bastante particular. Aunque por razones de desarrollo físico, socioafectivo e intelectual, los niños y las niñas no pueden reclamar su ciudadanía y esta debe ser constituida a partir de las personas adultas, las personas adolescentes sí pueden, y deben, tener una mayor participación ciudadana, ya que poseen mayores niveles de autonomía y posibilidades expresivas que niñas y niños. Sin embargo, como se ha visto en apartados anteriores, contra los jóvenes y las jóvenes se manifiesta de manera más violenta la negación, por la población adulta, de su carácter de 
sujetos; ese desconocimiento del carácter de sujeto de las personas adolescentes por parte del mundo adulto se expresa en espacios íntimos, como la familia, mediante relaciones unilaterales de autoridad, lo mismo que en espacios públicos como la escuela.

Como cierre, quiero destacar la idea de que la necesidad de salir es imperiosa y determinante en la adolescencia. Ante tal necesidad, las personas adultas (principalmente los familiares del sujeto adolescente) tienden a reaccionar de forma autoritaria, cuando lo que la juventud necesita es comunicación y comprensión, pues la demanda a dejar el ambiente familiar para incorporarse a otros ámbitos es parte de esta etapa de su desarrollo. Al carecer de ritos de pasaje claramente establecidos, corresponde a las personas adultas en conjunto con la población adolescente —respetando la nueva noción de ciudadanía específica - intentar establecer formas para que esta salida resulte enriquecedora para todos.

Esta opinión de Diana apunta a esa responsabilidad de la sociedad en su conjunto en aras del respeto de los derechos de las personas adolescentes:

— ¿Usted se ha sentido a veces como Rapunzel?

-Sí, porque muchas circunstancias de la vida hacen que cualquier persona actúe, piense o viva en condiciones que no son las más deseadas, porque no vivimos solos.

Quiero finalizar esta interpretación de resultados presentando una reflexión en torno al enfoque de los derechos humanos y la lectura, que es el tema principal de este trabajo. ¿Qué relación puede establecerse entre la lectura y el ejercicio de una ciudadanía activa? ¿Cómo el acto de leer literatura puede permitir que el sujeto se inserte de manera diferente en su realidad? Existe una idea muy difundida que asocia la lectura con un ensimismamiento y separación de los otros que inhibiría la socialidad. Sin embargo, la lectura propicia una descontextualización o distanciamiento de la realidad más cercana, gracias a la cual el sujeto puede rechazar esa realidad como algo dado, para vislumbrar posibilidades de insertarse en ella de manera diferente (Petit, 1999). 


\section{Conclusiones}

A continuación presento las principales problemáticas que destacan las dos lectoras de este estudio en su interpretación del cuento "Rapónchigo":

a) La adolescencia como crisis. Las lectoras de este cuento incorporan, en sus respuestas, el discurso adulto que presenta la adolescencia como crisis. Para Inés, la bruja encerró a Rapunzel a los 12 años, porque es "la edad en que se cometen más errores y tonteras" y alude con ello a situaciones como el embarazo y las drogas.

b) La supuesta crisis de la adolescencia y el rechazo como reacción de la clase adulta. La confusión entre "adolescencia" y "pubertad" hace que se estigmatice a la persona adolescente y se la convierta en objeto de rechazo, lo cual se expresa en el maltrato que ejerce la bruja del cuento con la joven y el príncipe. Frente al estereotipo del adolescente problemático, las personas jóvenes reclaman que las situaciones por las que atraviesan no son exclusivas de su edad; efectivamente, si fuera necesario hablar de "crisis", esta palabra debería aplicarse por igual a todos los componentes de la sociedad, asignándoles su cuota de responsabilidad a las instituciones y estructuras sociales.

c) Padres y madres ante la necesidad de sus hijos e hijas de salir. Según la forma como leen las adolescentes este cuento, ocupa un primer plano lo que el psicoanálisis denomina "mundo fantasmático", pues Rapunzel es vista como un producto (un "tesoro") de la historia de una madre marcada por la infelicidad y la soledad. De esa manera, la señora Gothel impide que la joven se construya como un sujeto diferente de ella. Por eso mismo, no puede permitirle que conozca a un hombre, ya que la joven le pertenece. Justamente Bettelheim ve, en este cuento, la historia de una niña que inicia su adolescencia y una madre celosa que le impide que alcance su independencia (representada por el príncipe). En la interpretación de la figura de la madre, las lectoras tienen posiciones encontradas: Diana la censura radicalmente y toma partido por Rapunzel, mientras que Inés identifica bruja y progenitores y le atribuye un carácter benéfico a su actitud represiva en contra de la hija, que puede explicarse por la "resistencia al cambio", la "culpabilidad adolescente" y el tópico de "por tu propio bien".

d) Castigos contra comunicación. Siendo tan importante en la adolescencia el contacto con otros y estando presente una sensación de muerte, el castigo que la bruja impone a 
Rapunzel (de enviarla a un lugar deshabitado y carente de vida) puede interpretarse como una sanción extrema. Así lo lee Inés, para quien ese castigo es como sería para ella que la privaran de la música, la televisión, el teléfono celular y las salidas. Diana, por su parte, lo analiza a la luz de quien impone la sanción, como una manifestación de dominio de la bruja que responde a su propia flaqueza; coincide con lo planteado por Alice Miller al explicar la necesidad de poder que lleva a las personas a dominar y castigar a los más débiles (en este caso, los niños, niñas y adolescentes) como una forma de identificarse con el agresor de que fueron objeto en su infancia. La aplicación de castigos es una respuesta del adultocentrismo para controlar a las personas jóvenes y responde, en muchos casos, a la propia inseguridad que revive la población adulta.

e) El enfoque de los derechos humanos. Al plantear su defensa de Rapunzel, las lectoras introducen en su discurso el enfoque de los derechos humanos, dentro del cual se identifica el derecho a la libertad desde una perspectiva renovadora, pues toca ciertas fibras sociales, en particular espacios antes considerados de la intimidad, como la familia y la escuela. Tratándose de sujetos adolescentes, como es el caso de las lectoras participantes en esta investigación, ello reviste una importancia especial, porque los visibiliza como sujetos de derecho, a la vez que destaca que la relación que establecen con las personas adultas está mediada por el poder.

Como conclusión general, puedo afirmar que la lectura y comentario del cuento "Rapónchigo" hace posible que una serie de experiencias particulares que los sujetos adolescentes viven como únicas, ingresen en el circuito de conocimientos generales al relacionarlas con los discursos y problemáticas en que se insertan. En otras palabras, es posible que, por medio de la lectura de este cuento y la formulación de interrogantes que apelen a la vivencia del sujeto, este sea capaz de dejarse "iluminar" por el texto, lo cual contribuirá a la elaboración de su subjetividad.

\section{REFERENCIAS}

Bajtín, Mijail. (1986). Problemas de la poética de Dostoievski. México: Fondo de Cultura Económica.

Baldiz, Manuel y Rosales, María Inés. (2005). Hablando con adolescentes. Madrid: Biblioteca Nueva. 
Bettelheim, Bruno. (1988). Psicoanálisis de los cuentos de hadas (S. Furió, trad.). Barcelona: Crítica.

Bloch, Dorothy. (2000). "Para que no me coma la bruja". Fantasía y miedo de los niños al infanticidio (4a. ed.; M. D. Llera Chocán, trad.). México: Siglo XXI.

Cruz, Sonia. (2004). Apuntes del curso "Poblaciones con Necesidades Educativas Especiales II", Maestría en Psicopedagogía, Universidad de La Salle, tercer cuatrimestre.

Dolto, Françoise. (1999). La educación en el núcleo familiar. Preguntas, inseguridades y límites (T. Amo, trad.). Barcelona: Paidós.

. (1993). Palabras para adolescentes o el complejo de la langosta (E. Gudiño, trad.). Buenos Aires: Atlántida.

. (1990). Cuando los padres se separan (I. Agoff, trad.; $2^{\mathrm{a}}$. ed. en México). México: Paidós Mexicana.

Etcheberry, J. y otros. (2006). Problemas en la adolescencia. Recuperado el 2 de mayo del 2006, de http://www.maristas.com.ar/champa/poli/derecho.adol.htm

Fedida, Pierre. (1979). Diccionario de Psicoanálisis (G. Perucchi, trad.). Madrid: Alianza.

Fernández Mouján, Octavio. (2002). Abordaje teórico y clínico del adolescente. Buenos Aires: Nueva Visión.

Fize, Michael. (2001). ¿Adolescencia en crisis? Por el derecho al reconocimiento social (A. Álvarez Urbajtel, trad.). México: Siglo XXI.

González Vargas, Laura. (2004). Adolescencia: una etapa de experiencia y aprendizaje. Tesis de Maestría, Universidad de La Salle, Costa Rica.

Grimm, Jacob y Wilhelm. (1995). Cuentos (P. Gálvez, trad.). Madrid: Alianza.

Güendel, Ludwig. (2000). La política pública y la ciudadanía desde el enfoque de los derechos humanos: la búsqueda de una nueva utopía. En S. Reuben Soto (editor científico). Política social. Vínculo entre Estado y sociedad (pp. 169-217). San José: Editorial de la Universidad de Costa Rica.

Krauskopf, Dina. (2000). Participación social y desarrollo en la adolescencia. Adolescencia y salud, 2(1). Recuperado el 26 de diciembre del 2006, de http://www.binasss.sa.cr/revistas/ays/2n1/art8.htm

Larrosa, Jorge. (1998). La experiencia de la lectura. Estudios sobre literatura y formación ( $2^{\mathrm{a}}$. ed.). Barcelona: Laertes.

Liaudet, Jean-Claude. (2002). Dolto para padres (R. Alapont, trad.). Barcelona: Plaza \& Janés. 
Mannoni, Maud. (1984). El niño retardado y su madre (R. Núñez, trad.). Buenos Aires: Paidós.

Miller, Alice. (1998). Por tu propio bien. Raíces de la violencia en la educación del niño (J. del Solar, trad.). Barcelona: Tusquets.

Petit, Michelle. (2001). Lecturas: del espacio íntimo al espacio público (M. y M. Paleo, D. L. Sánchez, trads.). México: Fondo de Cultura Económica. (1999). Nuevos acercamientos a los jóvenes y la lectura (R. Segovia y D. L. Sánchez, trads.). México: Fondo de Cultura Económica.

Real Academia Española. (2001). Diccionario de la lengua española (21 ${ }^{\mathrm{a}}$. ed.). Madrid: Espasa-Calpe.

Rojas Torres, Lilliana. (2002). El/la adolescente: mitos y constructos. Tesis de Maestría, Universidad de La Salle, Costa Rica.

Sarland, Charles. (2003). La lectura en los jóvenes. Cultura y respuesta (D. L. Sánchez, trad.). México: Fondo de Cultura Económica.

Sarto, Montserrat. (1998). Animación a la lectura con nuevas estrategias (J. A. Marina, pról.). Madrid: Ediciones S.M.

Tolstoi, León. (1991). Infancia-Adolescencia-Juventud. Recuerdos. México: Porrúa. 